\title{
O Movimento Sindical na Universidade Pública Brasileira*
}

pedro Rabelo Coelho

Universidade Federal de Santa Maria (UFSM)

Compreender as transformações do modo de produção capitalista neste final de século tanto no plano da conjuntura internacional quanto da nacional, buscando explicar a crise da universidade pública brasileira e reconhecer os desafios que se apresentam aos que lutam na perspectiva de integrar o trabalho acadêmico ao processo politico de construção de uma sociedade democrática: tais são os objetivos deste estudo. Ele está organizado em duas partes. A primeira aborda a "nova ordem econômica internacional" (NOEI), destacando principalmente o aparecimento e a atuação da elite orgânica internacional e a revolução científicotecnológica com suas conseqüências para a divisão do trabalho e a organização coletiva dos trabalhadores. A segunda parte discute a problemática dos docentes universitários enquanto trabalhadores e seu envolvimento nas lutas politico-sindicais, apontando, ao final, o desafio com que se depara o movimento docente para a construção de uma verdadeira universidade pública.

\section{A nova ordem econômica internacional e suas implicações para os movimentos sindicais}

Uma das marcas mais evidentes da ordem econômica internacional gerada pelo modo de produção capitalista na segunda metade do século XX (no periodo pós-guerra) foi a concentração das decisões políticas nas mãos de uma reduzida "elite do poder", que passou a dispor de sofisticados

-Este trabalho foi elaborado a partir da tese de doutorado A questão politico-sindical na universidade brasileira. UFRGS, Faculdade de Educação, Programa de Pós-Graduação em Educação, 1993. O projeto de pesquisa que subsidiou a elaboração da tese contou com o apoio financeiro do CNPq, da FAPERGS e do INEP. 
controles técnico-econômicos, incluída a influência cada vez mais poderosa dos meios de informação, para se legitimar junto às massas.

Wright Mills, já na década de 50 , estudou a transformação que ocorria na sociedade americana, com a implantação do "New Deal" de Roosevelt e sua política intervencionista (keynesianismo). Segundo ele, tratava-se de uma tentativa desesperada das classes dominantes para salvar o capitalismo, para reduzir o sombrio exército de desempregados, buscando compor um equilíbrio dos grupos de pressão. As funções do Estado foram ampliadas, numa verdadeira economia de guerra, em que as grandes empresas e o setor militar foram engajados no setor político. Dessa forma, consolidou-se a "elite do poder", onde os "homens da política" - os empresários e os militares — permutavam papéis entre si. Mas a chave estrutural desse processo de concentração de poder era o setor econômico. Paralelamente, observava-se a massificação da sociedade, a redução das associações e o enfraquecimento dos laços primários, com a crescente influência dos meios de comunicação de massa. Esta era, segundo Mills (1981, cap. 13), uma tendência estrutural da sociedade moderna.

O modelo econômico keynesiano possibilitou salvar o capitalismo liberal, que por pouco não sucumbiu nas duas guerras mundiais ${ }^{1}$. Politicamente, estabeleceu-se uma aliança entre o capital e o trabalho organizado. Em vez de combater diretamente os sindicatos, a classe hegemônica buscou, fazendo concessões econômicas, integrá-los como colaboradores. O capitalismo monopolista do pós-guerra passou a apresentar-se como defensor da democracia e dos direitos humanos, aceitos como valores universais. A Declaração da ONU, de 1948, foi um marco dessa nova direção assumida pelo capitalismo. As Resoluções da OIT são demonstrações de que os direitos sindicais foram assimilados ${ }^{2}$.

$\mathrm{Na}$ evolução do capitalismo monopolista, dois aspectos foram fundamentais: a constituição de uma elite intelectual orgânica internacional

Eric Hobsbawn (1990) afirma: "É impossível compreender a história inteira de nosso século a nao ser que lembremos que o velho mundo do capitalismo global e da sociedade burguesa em sua versão liberal caiu em 1914, e que durante os 40 anos seguintes o capitalismo tropeçou de uma catástrofe para outra. Mesmo conservadores inteligentes não teriam apostado em sua sobrevivência".

${ }^{2}$ Ver CMOPE (1983) Esta publicação da CMOPE traz o texto da Convenção 87 e de outras importantes convenções da OIT sobre o direito de organização e negociação coletiva do trabalho (Convenções 98, 151, 154e 111). 
e o desenvolvimento da ciência e da tecnologia, especialmente no setor da informação, aplicada inclusive para fins militares. Na década de 70, quando o modelo de Estado Nacional, que havia se legitimado como promotor do bem-estar (Welfare State), entrou em crise, estabeleceramse as bases daquela que passaria a ser chamada de "Uma Nova Ordem Econômica Internacional". A crise se expressava pelo fracasso dos Estados Unidos na guerra do Vietnam e também pelo desgaste dos governos ditatoriais em nações do Terceiro Mundo, governos esses que tinham sido implantados com apoio norte-americano (caso do Brasil e, depois, do Chile, entre outros). Tornava-se insustentável manter a escalada da "guerra fria" como estratégia para derrotar a ameaça do comunismo internacional. Não bastava combater de fora o avanço comunista, num enfrentamento direto, pois a perspectiva de que surgissem vários "vietnames" era aterradora. O domínio internacional capitalista deveria ser alcançado doravante pela via democrática. Arma-se a política da détente, admite-se a presença dos partidos socialistas europeus (socialdemocracia), elabora-se a ideologia dos "direitos humanos" — carrochefe da nova política externa americana, na Administração Carter buscando reverter a crise da derrota na Indochina. Estrutura-se, aos poucos, o novo projeto de dominação capitalista internacional (Assman, 1990; Santa Ana, 1979; Dreifuss, 1987).

Em 1974, a ONU fez sua Declaração de "Uma Nova Ordem Econômica Internacional" (NOEI), com o objetivo de estabelecer uma "ordem" que promovesse "o desenvolvimento econômico e social de todos os cidadãos do mundo, baseado na igualdade, interdependência, interesse comum e cooperação entre todos os países". Essa ordem, segundo a Declaração da ONU, deveria reduzir a enorme defasagem entre os países desenvolvidos e em desenvolvimento. Nesse mesmo ano, a Conferência da Unesco estabeleceu uma resolução enfatizando a importância dos fatores socioculturais como estratégia para alcançar a "NOEI"

\footnotetext{
${ }^{1}$ Contrastando com as declarações da ONU c da Unesco e com a propaganda dos "Direitos Humanos", o que se sucedeu foi uma maior acumulação capitalista em nível internacional, agravando-se a distância entre os países mais ricos e os mais pobres. $\mathrm{O}$ "crescimento" do PIB na América Latina, na década de 80, foi negativo (-10\%); em contrapartida, a América Latina exportou capital no montante de 200 bilhões de dólares. No Brasil, o salário mínimo entre 1980 e 1990 sofreu uma perda real de 46\% (Ver Folha de São Paulo, 28/07/91, p.I-3).
} 
É dentro dessa nova conjuntura internacional que se inserem as mudanças político-econômicas do Brasil (e da América Latina, em geral) no final da década de 70 e início dos anos 80 (Marini, 1987). A "abertura democrática" era a adaptação do Brasil à NOEL Tratava-se de consolidar a hegemonia do capitalismo oligopolista internacional pela via democrática. Então, as duras conquistas dos trabalhadores, dos movimentos sociais e sindicais, foram assimiladas e enquadradas na nova ordem econômica, porém, com as especificidades brasileiras.

No plano internacional, a década de 80 caracteriza-se pela vitória do neo-liberalismo, desintegrando-se a política do "New Deal" com a chamada "crise fiscal" do Estado, que se expressa nos fenômenos do déficit público e do crescimento da inflação. Nos Estados Unidos, na Inglaterra, na Alemanha, no Japão e em outros países, governos conservadores são legitimados democraticamente, com a promessa de recuperar a economia e conter a inflação. Ao mesmo tempo, as organizações sindicais são integradas à nova ordem, atuando freqüentemente como verdadeiras organizações empresariais. O "capitalismo dos sindicatos" foi um mecanismo que possibilitou esvaziar a pressão dos movimentos operários (Bernardo, 1987).

Guardadas as proporções e respeitadas as diferenças, permanece a mesma lógica do período pós-guerra. Há um fortalecimento do controle político em nível internacional, que é exercido pelo sistema econômicofinanceiro, sendo o FMI uma das suas mais significativas instituições. Aumenta o fluxo de capitais em favor dos monopólios e oligopólios, integrados em nível internacional. Nos Estados Unidos e Europa aumentam os gastos militares e os investimentos em alta tecnologia. Consolida-se a NOEI como resultado, de um lado, da supremacia tecnológica sob o controle da classe dominante internacional e, por outro lado, da capacidade demonstrada pela mesma classe de impedir que os movimentos contestatórios se organizassem a ponto de colocar o sistema em risco. Em outros termos, os focos de conflito foram contidos e mantidos nos limites da ordem econômica capitalista.

Mais, os movimentos reivindicatórios que lutavam por direitos sociais sofreram um revés na década de 80 . A ideologia conservadora da 
"Nova Direita" com sua mensagem de liberdade de escolha, de competição e competência, de lógica do mercado e anti-estatismo, de descentralização e privatização, mensagem esta trabalhada no campo psicossocial e cultural com o poder imensurável das modernas técnicas de comunicação (midia), ganhou terreno nesta "guerra de posições" (Apple, 1988a e 1988b; Finkel, 1990; Carnoy, Levin, 1987, p.281-302).

A revolução técnico-científica foi um elemento essencial para a consolidação da NOEL Não se trata apenas de inovações específicas, mas de uma transformação mais profunda que se inscreve na própria lógica do modo de produção. O conhecimento científico é cada vez mais entendido e tratado como capital. Em decorrência, intensifica-se o controle dos grandes grupos econômico-financeiros sôbre a produção de conhecimentos, particularmente sobre a universidade. "Controlar a produção de conhecimento técnico era importante para a produção sistemática de patentes e para a monopolização do mercado" (Apple, 1989, p.65).

O controle sobre a produção da ciência efetivou-se tanto pelo monopólio sobre patentes quanto pela reorganização da vida universitária, especialmente pela mudança nos currículos. Essa interferência contou com a intermediação do Estado. Isto se explica porque os investimentos em formação de capital humano e recursos tecnológicos são excessivamente caros e o retorno não é imediato. Então o Estado assume esses investimentos e depois repassa os resultados para o setor privado (Apple, 1989, p.69).

Há uma clara ligação entre o deslocamento da atuação do Estado capitalista para o centro mesmo da economia e a intensificação do controle sôbre a produção técnico-científica (Poulantzas, 1986, p.204-215). Os agentes mais dinâmicos dessa transformação são os conglomerados transnacionais, oligopólios que atuam em escala mundial, estabelecendo uma estrutura interligada via satélite e telex, com apoio em sistemas de processamento e banco de dados, operando sem interrupção nas 24 horas do dia em escala global. Os conglomerados compreendem bancos e instituições financeiras integrados a complexos industriais e a poderosas íradingcompanies, possibilitando impor em ritmo cada vez mais acelerado 
a acumulação e centralização de capitais. Baseados no imenso poder financeiro de que dispõem, esses conglomerados investem pesadamente em Pesquisa e Desenvolvimento, e isto lhes assegura uma liderança e um controle crescentes sobre o mercado, em nível internacional (Rattner, 1988, p.5-12; Reich, 1991).

Mas isso só foi possível porque se constituiu um núcleo de vanguarda político-intelectual, uma elite orgânica internacional que se diferenciou do conjunto das classes dominantes dos diversos países, possibilitando sua articulação para a intervenção eficaz no universo socioeconômico e cultural. Dreifuss (1987, p.21-31) utiliza a análise gramsciana para explicar como essa "elite orgânica internacional" possibilitou a constituição do empresariado nos diversos países como verdadeira classe. Tal elite atua como "cérebro" da classe, uma espécie de "estado maior" que faz a mediação para a formação de blocos de poder ou "frentes móveis de ação". Essa atuação mediadora no interior das classes dominantes é fundamental para a articulação hegemônica e a superação de conflitos entre frações de classe, visando garantir a coesão interna. Trata-se de uma ação de natureza essencialmente políticoideológica, exercida pela elite orgânica enquanto "pensadora de uma classe" ou "parcela esclarecida da burguesia".

Essas mudanças tiveram profundas conseqüências para a divisão do trabalho e para os movimentos sindicais, em nível internacional. Dirse-ia que o lema marxista "Operários... uni-vos" foi melhor captado pela classe dominante, que consolidou sua organização em nível internacional, conseguindo impedir que o movimento operário se estruturasse como classe revolucionária na perspectiva proposta por Marx e Engels. Em vez da "internacional comunista" houve o fortalecimento da "internacional capitalista" (Dreifuss, 1987). O empresariado, este sim, está efetivamente articulado como "classe para si" em nível internacional e assume o jogo político de forma ostensiva.

As mudanças ocorridas no mundo do trabalho são consideráveis. As técnicas de produção industrial estão se modificando radicalmente. Há uma crescente automação, reduzindo-se os "exércitos de trabalhadores", anunciando-se o fim da "época fordista", o declínio das fábricas 
gigantes e estandardizadas, com administração hierarquizada e centralizada. A classe operária já não cresce nos países do primeiro mundo. Alterou-se bastante a estrutura da divisão internacional do trabalho, acarretando uma descentralização, uma regionalização das organizações operárias, uma dispersão (Hobsbawn, 1989). Por outro lado, os sindicatos passaram a ter função essencial para a manutenção da ordem na empresa e na sociedade, mediante o jogo corporativista de concessões periódicas sobre salários e condições de trabalho. "Para os capitalistas tornou-se (o sindicato) um 'mai necessário'... e, para os operários, tornou-se uma entidade de tipo corporativo que protege seus interesses profissionais e é útil na negociação de salários. Assim, os sindicatos, que foram uma conquista do movimento operário, tornaram-se elementos que o sistema capitalista pode não apenas domar, mas repor" (Chaui, 1982, p.129).

Um aspecto importante dessa mudança nas relações capitaltrabalho foi o grande crescimento do chamado setor terciário, constituindo um novo tipo de assalariado, com uma consciência de classe muitas vezes ambígua, trazendo implicações enormes para o movimento sindical. Os empregados em serviços técnicos e burocráticos constituíam, na fase anterior do capitalismo, um setor intermediário entre a alta hierarquia (proprietários e dirigentes) e os níveis inferiores (operariado). Mas o avanço das técnicas de controle, na linha da informatização e da automação, tornou a maioria das funções técnicas uma rotina de atividades préprogramadas. Em decorrência, "a maioria dos empregados deixam de ser representantes, tornando-se produtores e executando um processo racionalizado de alto para baixo: o capital tem cada vez menos necessidade de pessoas de confiança porque não precisa mais delegar autoridade e, sim, objetivos e funções" (Gorz, 1989, p. 171).

A proletarização dos setores intermediários favoreceu a sindicalização como forma de reação à perda de privilégios, inclusive à degradação dos níveis de remuneração. Observa-se, contudo, um caráter ambíguo nos movimentos sindicais desses setores, pois embora tenham sido reduzidos à condição de proletários, trazem o peso de uma tradição cultural com uma arraigada consciência de posição privilegiada, que tem enorme efeito anti-sindical. Sua luta reivindicatória é marcada quase sempre 
pelo caráter corporativo. Lutam contra a perda de privilégios, não contra o sistema que cria privilégios.

As transformações tecnológicas possibilitaram ao capital destruir, em grande parte, a força da luta operária e do movimento sindical em geral. A ampliação da massa de assalariados foi acompanhada da alienação, da perda de controle sobre o processo de trabalho, da fragmentação e dispersão dos trabalhadores. O desaparecimento da secular clivagem entre trabalho manual e trabalho intelectual poderia significar o fim de uma concepção estreita de "classe operária" (Lojkine, 1990, p. 15-16). Porém, à medida que se amplia a "classe operária" e se desfaz a diferenciação (todos agora são "operários"), enfraquece-se a perspectiva de os trabalhadores se constituírem como uma classe autônoma capaz de conquistar o poder e estabelecer o "reino da liberdade", como defendia Marx (Gorz, 1987, p. 115-123).

Dessa forma, o capitalismo oligopolista vem obtendo sucesso em reduzir a autonomia dos trabalhadores. Cada vez mais alienada, fragmentada pela crescente divisão do trabalho e pelo jogo corporativista, a massa dos assalariados já não ameaça a classe burguesa. Esta consolidou sua organização em âmbito mundial, acumulando e concentrando o capital, dispondo a seu favor do enorme poder da alta tecnologia.

O movimento sindical parece ter sido profundamente afetado enquanto força organizadora e unificadora dos trabalhadores para atenuar os efeitos da exploração do trabalho e da acumulação do capital. Parece haver um ceticismo crescente, principalmente entre os trabalhadores jovens, com relação às organizações sindicais, enquanto as interpretações conservadoras liberais ("mercado livre") ganham terreno, estimulando o comportamento competitivo, a heterogeneidade e mesmo o antagonismo entre grupos de trabalhadores (Offe, 1989). As ameaças ao trabalho, como o risco de desemprego, são vivenciadas pela maioria numa perspectiva individualista. Cada vez mais as pessoas se interessam por sua vida pessoal, não tanto pelos problemas políticos e sociais. Em conseqüência, as classes dirigentes já não sofrem tanto as pressões populares.

Mais recentemente, a crise do leste europeu, com a derrubada do muro de Berlim e o desmantelamento da URSS, possibilitou ao capitalismo 
internacional ampliar ainda mais seus espaços na exploração da classe trabalhadora. Em geral, os movimentos e organizações sindicais foram fortemente afetados com a substituição da utopia socialista pela lógica capitalista de mercado. A revolução científico-tecnológica, fator fundamental na implantação da nova ordem capitalista em escala global, veio ampliar o processo de alienação dos trabalhadores, dificultando a ação sindical na perspectiva classista.

Pelo visto, fica a impressão de que se chegou ao "fim da história", sendo a racionalidade capitalista, a lógica do mercado, a única possibilidade de construção da sociedade futura. Os meios de comunicação, sob o controle de poderosos oligopólios, difundem essa ideologia em todos os campos (do conhecimento, das artes, do lazer etc). Contudo, a realidade é bem mais complexa.

Observam-se atualmente sinais claros de que a nova ordem econômica não superou os velhos problemas do capitalismo. A balcanização do leste e centro europeus, com a explosão de conflitos étnicos e o recrudecimento da miséria de enormes contingentes populacionais, o ressurgimento de movimentos nazistas, a ampliação do desemprego e o aumento do número de pobres inclusive nos países mais desenvolvidos estão indicando o aprofundamento da crise do capitalismo oligopolista. Acirram-se as contradições no próprio núcleo do sistema, que não consegue consolidar um novo equilíbrio internacional estruturado em blocos. Por enquanto, para solucionar os constantes conflitos em diversos pontos do globo, os Estados Unidos vêm se firmando no papel de "gendarme internacional". Porém, à medida que os conflitos sociais se agravam e se generalizam, torna-se evidente a necessidade de buscar uma nova racionalidade.

O desafio que está posto hoje aos trabalhadores e suas organizações é encontrar alternativas capazes de barrar o enfraquecimento da ação coletiva, de conter o avanço da fragmentação e do jogo corporativista que favorecem a dominação oligopolista. Essas alternativas terão que ser políticas, no sentido de que a própria sociedade deve decidir as regras do ogo. Como afirmou Ohlweiler (1986, p. 135), "... à medida que o capitalismo monopolista dá lugar a formas novas de envolvimento do 
Estado na esfera da produção, o próprio processo de valorização do capital será cada vez mais afetado por critérios e decisões de natureza política". Trata-se da sobredeterminação do político sobre o econômico, conforme analisou Poulantzas (1986, p.48). Por sua vez, Marcuse já advertira para o risco de o capitalismo contemporâneo destruir ou anular as forças de oposição, criando uma sociedade sem alternativas. Para ele, a racionalidade tecnológica precisa cada vez mais ser dependente da direção política "do esforço coletivo para conseguir uma existência pacífica, com as metas que os indivíduos livres possam escolher para si" (Marcuse, 1982, p.217). E Gorz (1987, p.138) assim declarou: "a existência de um movimento de lutas sociais é a alavanca que põe a sociedade em posição de agir sobre ela mesma e de fundar liberdades, um Direito e um Estado novos".

Essa perspectiva de luta política, buscando a transformação da sociedade atual pela ação no interior do próprio estado capitalista, denunciando suas contradições, ampliando o espaço democrático, coloca para as organizações dos trabalhadores uma nova dimensão, um outro horizonte, capaz de ultrapassar as limitações impostas pelo capitalismo oligopolista $^{4}$.

\section{A crise da Universidade Pública Brasileira e as perspectivas de luta do movimento sindical dos docentes}

As Instituições de Ensino Superior, há algum tempo, vêm sofrendo uma crise de identidade, a qual tem muito a ver com as transformações do modo de produção capitalista. A universidade deixou de ser uma instituição definida como "sede da sabedoria" \{sedes sapienüae), que se pretendia neutra diante dos conflitos político-sociais mas que, de fato, formava a elite pensante (intelectuais orgânicos) das classes dominantes. Embora ainda cumpra esse papel, a instituição universitária vem se tornando um

\footnotetext{
${ }^{4}$ Segundo Camoy (1988, p.326): "Poulantzas na França, Offc na Alemanha, Ingrao e Bobbio na Itália, 0'Connor, Castells, Wolfe e outros nos Estados Unidos, todos argumentam a favor de uma forma ou outra de transformação através da democracia capitalista, para expandir o poder da massa sobre recursos já controlados pelo Estado e para expandir o próprio poder político da massa, através de contradições implícitas no processo democrático".
} 
espaço público, aberto também aos interesses dos dominados, participando de movimentos e lutas sociais que objetivam a construção de uma sociedade democrática.

O capitalismo monopolista, em seu desenvolvimento, provocou a expansão quantitativa e a massificação dos intelectuais. Os profissionais liberais de antes (incluindo os professores universitários, em geral) foram transformados em trabalhadores intelectuais assalariados. A maioria deles foi alijada do controle e do poder de decisão sobre o processo de trabalho. A chamada elite intelectual é cada vez mais um setor profissionalizado da classe dominante, mas de tamanho reduzido. As universidades, que historicamente se identificavam como agências formadoras dessa elite, constituem hoje instituições bastante diferenciadas entre si (com vários padrões de universidades). Hoje não se pode mais considerar as universidades em geral como instituições exclusivamente a serviço da burguesia.

Os intelectuais, em sua maioria, tornaram-se trabalhadores assalariados e isto fez com que, em parte, fosse superada a clássica divisão entre trabalho manual e trabalho intelectual, que era um elemento fundamental das fases anteriores do capitalismo. O assalariamento e a profissionalização do professor universitário trouxeram para a academia a discussão de problemas que eram próprios do "mundo do trabalho", caracterizando o conflito capital-trabalho. Muitos docentes passaram a utilizar a luta político-sindical, aproximando-se dos trabalhadores em geral, integrando-se às suas organizações.

Por outro lado, o trabalho docente, tal como aconteceu com os serviços técnico-burocráticos, foi afetado pelo avanço tecnológico. Desponta a tendência do empresariamento das instituições de ensino. Reconversão profissional, pacotes de currículo, treinamentos, requalificação, busca da produtividade etc, vão sendo incorporados ao processo de ensino por imposição das transformações tecnológicas. Os professores poderão perder ainda mais o controle do processo de trabalho à medida que microcomputadores e videocassetes, com seus programas $\mathrm{e}$ 
pacotes instrucionais, invadirem as salas de aula. O risco que está colocado é de que o professor se torne um monitor, um "apêndice da máquina" ${ }^{5}$.

Contudo, a adaptação a novas tecnologias não implica necessariamente a perda da autonomia no local de trabalho. $\mathrm{O}$ controle sobre o processo de trabalho é, fundamentalmente, um processo ideológico que se faz mais sôbre os fins que sobre os meios. É perfeitamente possível conciliar uma maior autonomia nos locais de trabalho com a lógica do sistema econômico como um todo, uma vez que os fins estejam sob o controle do sistema. Isso tem uma implicação importante para os movimentos dos trabalhadores: à medida que a luta se restringe à busca de autonomia e liberdade de organização no local de trabalho e à defesa de privilégios (numa perspectiva sindical corporativista), ela pode se enquadrar muito bem na lógica dominante do capitalismo monopolista. Aliás, sempre interessou aos capitalistas manter os trabalhadores lutando apenas por salário e condições de trabalho, afastando-os assim, da luta política.

Parece defensável a hipótese de que as transformações trazidas pela NOEI (assimiladas no Brasil ao seu modo de país capitalista dependente) explicam, em grande parte, a crise da universidade brasileira nos anos 80. Houve o privilegiamento de setores que interessam à "reconversão", por favorecer a absorção de alta tecnologia. Segundo a lógica dominante da concentração internacional do capital, nao interessa o desenvolvimento das Instituições de Ensino Superior como um todo, ou seja, em todos os seus setores. Daí por que não é surpreendente que o Governo Sarney (1985-1990) tenha orientado a política do ensino superior no sentido de criar "centros de excelência" e "laboratórios avançados", política esta que teve continuidade nos governos Collor e Itamar. Apenas esses setores seriam privilegiados, por atender aos grandes oligopólios, enquanto a maior parte do sistema público de ensino superior é atirada ao abandono, ao sucateamento.

${ }^{5}$ Cf. Lawn e Ozga (1988) Os autores discutem o movimento sindical dos professores na Inglaterra, com o surgimento da "proletarização" e o subseqüente empresariamento do ensino. A conclusão a que chegam é que o trabalho docente cada vez mais se assemelha ao trabalho de escritório, isto é, está perdendo sua especificidade, perante o avanço da tecnologia. 
Tanto a política econômica quanto a política de ciência e tecnologia dos últimos governos tiveram forte impacto negativo sobre a universidade. No caso da universidade pública, especificamente, os docentes são funcionários do Estado, que é responsável pela manutenção da própria universidade. Na medida em que o Estado brasileiro é mais privado do que público, controlado pela "Sociedade Política Dominante" e suas "elites orgânicas" (Dreifuss, 1987), a universidade é pressionada a se submeter à mesma ordem política. Pensar "uma universidade democrática e livre, numa sociedade amordaçada, é um delírio", afirma Romano (1989, p.39). Contudo, o Estado não é exclusivamente um "aparelho das classes dominantes", mas um espaço que condensa as diversas contradições de uma sociedade (Poulantzas, 1986). Sendo assim, é possível aos setores e classes sociais subalternas lutarem dentro do próprio aparelho do Estado pela conquista de uma ordem social democrática. Nesse sentido, o espaço institucional da universidade é importante, como percebeu desde o início a Associação Nacional dos Docentes das Instituições de Ensino Superior (ANDES), quando estimulou e se envolveu na luta pela democratização da universidade ${ }^{6}$.

O chamado "Movimento Docente" foi marcado desde suas origens pelo aspecto político, de contestação do regime autoritário, de luta pela anistia, por eleições diretas, pela Constituinte, enfim, por um Estado democrático. O movimento para a escolha de um reitor através do voto direto da comunidade universitária surgiu no contexto da luta ampla pela democratização da sociedade. O movimento docente passou a se envolver cada vez mais na luta pela conquista da democratização interna e no jogo político junto aos parlamentares (Congresso Nacional) e às organizações da sociedade civil (entidades científicas, sindicais, partidárias). $O$ fato de ue, aos poucos, muitos reitores foram eleitos por votação direta dos ocentes, funcionários e estudantes, contribuiu para fortalecer a luta olítico-sindical na universidade. Isso ficou claramente demonstrado em

A Associação Nacional dos Docentes das Instituições de Ensino Superior (ANDES) foi fundada num Congresso Nacional de Docentes realizado em Campinas (SP), de 17 a 20/2/81. Em 26 de novembro de 1988, no II Congresso Extraordinário, realizado no Rio de Janeiro, a ANDES foi transformada em Sindicato Nacional dos Docentes das Instituições de Ensino Superior(ANDES- 
diversas greves das Instituições Federais de Ensino Superior (IFES), especialmente nas de 1984, 1987 e 1991, onde o papel mediador dos reitores foi importante para superar os confrontos.

No entanto, assim como a luta por salário e melhores condições de trabalho vem sendo assimilada de forma a não colocar em risco a lógica do sistema econômico, assim também as conquistas democráticas nas universidades pouco têm significado transformação das estruturas herdadas do passado. Essas duas lutas, a reivindicatória (salarial) e a política (eleitoral), têm se somado para, de certa forma, manter as universidades ocupadas consigo próprias, no jogo corporativista próprio da sociedade capitalista contemporânea.

As lideranças do movimento docente percebiam já no início da década de 80 que era necessário empenhar-se na construção de uma nova proposta de universidade, articulando a defesa da carreira docente e da escolha dos dirigentes numa concepção de universidade pública, gratuita e autônoma, comprometida com uma sociedade realmente democrática. As linhas gerais da "Proposta da ANDES para a Universidade Brasileira" foram divulgadas em 1982 (Cadernos ANDES, n.2, 1986). Desde então pouco se avançou em face do confronto politico-ideológico com o governo. De um lado, as energias foram gastas na luta por salário e para garantir o direito de eleger os dirigentes das Instituições de Ensino Superior (IES), buscando assim as lideranças das associações docentes e da ANDES sua legitimação como representantes da categoria dos docentes. Sem isso, talvez a própria universidade pública tivesse sido completamente privatizada. Mas, por outro lado, a proposta da ANDES não avançou também por causa das ambigüidades da própria categoria profissional dos docentes universitários.

O agravamento da crise econômica (a escalada da inflação e o arrocho salarial), a diminuição dos recursos destinados às instituições públicas e o avanço da privatização contribuíram para deixar a ANDESSN "entrincheirada" na defesa de suas posições. Conduzindo-se como organização sindical exemplar, dentro das normas jurídicas estabelecidas na Constituição e nas leis, a ANDES-SN está hoje consolidada no setor das IFES (não tanto nas IES estaduais, menos ainda nas IES particulares). 
O sindicalismo docente permanece tributário de contradições e ambigüidades que se ligam, em grande parte, ao caráter inconsistente que é próprio de organizações sindicais de trabalhadores do serviço público.

Muitas contradições decorrem da participação desses trabalhadores, ao mesmo tempo na estrutura do poder e no mercado de trabalho: enquanto técnicos e funcionários do Estado, atuam como formuladores e reprodutores da ideologia dominante, muitas vezes inconscientemente, planejando e operacionalizando (executando) a política oficial; enquanto empregados assalariados, defrontam-se com problemas comuns à massa dos trabalhadores e, por isso, tendem a reforçar as organizações que combatem o modelo econômico do Estado. No entanto, esse combate é muitas vezes conduzido de tal maneira que resulta no fortalecimento da própria burocracia estatal.

Tais contradições explicam porque muitas das conquistas da ANDES-SN acabaram modificadas na prática, sendo desvirtuadas por medidas hábeis do governo, que soube explorar as incoerências da categoria dos docentes. O plano de carreira dos docentes das IFES é um claro exemplo disto. Nele não foram definidas responsabilidades, divisão de poderes e tarefas, mas foram incluídas gratificações e um sistema de promoção caracterizado pela ausência de uma avaliação criteriosa do trabalho acadêmico. A própria degradação dos níveis salariais, imposta pela política econômica do governo, induziu os docentes à procura do regime de dedicação exclusiva, da promoção automática (por antigüidade), do concurso interno para professor titular, das gratificações por funções administrativas. O resultado disso tudo é que, após mais de dez anos de luta por um plano de carreira docente (essa luta é anterior à criação da própria ANDES), o mesmo se encontra completamente desvirtuado. $\mathrm{O}$ sindicato está sendo obrigado a assumir o desafio de elaborar um novo plano de carreira, que objetive a construção de uma universidade pública "de qualidade", dentro dos princípios de sua Proposta de Universidade. Nos últimos anos o tema "carreira docente" constou sempre da pauta dos "rincipais eventos da ANDES-SN.

Por outro lado, a política de arrocho salarial e de contenção de gastos públicos praticada pelo governo de forma autocrática, deixando 
de cumprir acordos e leis sancionados por ele próprio, gerou uma série de demandas judiciais que acabaram por desfigurar, na realidade, a isonomia salarial conquistada pelos docentes e funcionários das IFES em $1987^{7}$. Existem ainda os recursos do sistema de financiamento de pesquisas e os convênios com órgãos do próprio governo e com empresas privadas que possibilitam, na prática, uma renda suplementar aos salários, sem se falar na burla freqüente do regime de dedicação exclusiva. Dessa combinação perversa da política autoritária do governo e da persistência de práticas corporativas e clientelistas no interior das IES resulta também o enfraquecimento da luta sindical.

É característica dos intelectuais pequeno-burgueses uma certa incapacidade de se identificar com a massa dos assalariados. Eles (os intelectuais) "jamais contestam a validade de um dos elementos centrais do capitalismo e de qualquer sociedade de classes: a divisão entre trabalho intelectual e trabalho manual". A citação é de Décio Saes (1985, p. 179), que afirma enfaticamente: "(...) os intelectuais podem ser politicamente tudo (...) salvo ser contra a sua própria sobrevivência enquanto grupo". O mesmo autor acha "sugestiva" uma frase de Bourdieu: "Os intelectuais são uma fração (dominada) da classe dominante".

Disso decorre a tendência dos intelectuais de desvalorizar a luta sindical, a ação reivindicatória coletiva, quando esta assume a perspectiva de luta política. Não é por acaso que o assalariamento e a proletarização da classe média e dos trabalhadores intelectuais coincidem com a fragmentação e a corporativização da luta sindical. É um traço comum do Estado capitalista moderno fomentar o corporativismo no seio das classes trabalhadoras, evitando, assim, colocar em risco o domínio da classe burguesa.

A relativa incapacidade de organização coletiva da classe média, que decorre de sua própria posição no processo produtivo, onde tradicionalmente se diferenciava dos trabalhadores manuais (proletariado), favorece a tendência ao estatismo, isto é, a esperar que o Estado intervenha

' A Lei n ${ }^{\circ}$ 7.596, de 10 de abril de 1987, criou o Plano Único de Classificação e Retribuição de Cargos e Empregos (PUCRCE), que foi depois regulamentado pelo Decreto ${ }^{\circ}$ 94.664, de 23 de julho de 1987. 
para garantir-lhe os méritos. A ideologia da meritocracia, característica dos intelectuais pequeno-burgueses, foi habilmente explorada pelas classes dominantes. Na luta de enfrentamento entre as classes, os setores médios serviam para amortecer os conflitos, ocupando as posições intermediárias, aí incluído o aparelho burocrático do Estado. Quando a evolução do sistema econômico capitalista, em sua lógica de concentração e acumulação de riqueza, obtida pela divisão e expropriação do trabalho, conduziu ao assalariamento e à mercantilização do trabalho intelectual, a classe média custa a se organizar em sindicatos. E quando o faz, sua organização sindical é marcada pelo corporativismo, pela defesa de privilégios. O Estado, embora seja acusado por sua política econômica e denunciado como autoritário, é buscado como protetor, como guardião dos direitos "sociais", aí incluídos os "méritos" individuais, isto é, os privilégios ameaçados. "O trabalhador de classe média vive a ilusão da competência e do mérito individual, o que o torna particularmente receptivo à ideologia da ascensão social pelo trabalho e o desvia da organização e da luta coletivas" (Boito Jr, 1982).

A sindicalização do funcionalismo público no Brasil é uma questão recente e polêmica. Talvez seja este o aspecto que mais chama a atenção no movimento sindical nos últimos anos: o setor público foi, destacadamente, o que realizou maior número de greves e as greves mais longas (Almeida, 1988). No entanto, dadas as características do modelo sindical oficial ("sindicalismo de Estado") do Brasil, a amplicação do movimento sindical, na medida em que buscou o reconhecimento oficial (registro no Ministério do Trabalho) e se enquadrou na legislação vigente, acabou por fortalecer o próprio controle do Estado. O Brasil continua distante de uma organização sindical autônoma, independente do Estado, sustentada por opção dos próprios sindicalizados (sem imposto ou contribuições compulsórias), conforme indica a Convenção 87 da OIT. A demora da ratificação dessa convenção pelo Brasil deve-se não apenas à imposição arbitrária do Governo. O próprio movimento sindical, incluindo a CUT, foi cúmplice dessa situação.

Quanto à ANDES-SN, embora tenha se constituído sobre princípios diversos daqueles do sindicalismo corporativo oficial, apresenta 
também ambigüidades em sua organização de base, que decorrem do fato fundamental de que muitos docentes não se identificam como trabalhadores a ponto de se organizar e lutar coletivamente, de forma autônoma.

Desde o início do movimento docente (década de 70), lideranças das associações docentes percebiam que só teriam possibilidade de enfrentar a política oficial e obter ganhos políticos à medida que o movimento fosse forte em sua base e autônomo em relação ao Estado e às administrações das IES. As lutas por melhores salários e por carreira docente, que até certo ponto se confundiram, possibilitaram criar e consolidar a entidade representativa da categoria. O Estado, ao longo da última década, foi forçado a negociar com esse novo ator, um ator coletivo. Houve, ante o avanço do sindicalismo docente, um recuo do Governo (Vieira, 1990, p.72). Sem a resistência organizada da ANDES-SN, à qual se juntou aos poucos a da FASUBRA, a Universidade Pública não existiria mais na forma como se mantém. A privatização e o atrelamento aos interesses dos grupos econômicos oligopolistas teriam avançado muito mais.

No conflito que se estabeleceu com a política do governo, o sindicalismo docente fortaleceu-se e obrigou o governo a negociar. Neste sentido, a ANDES-SN contribuiu para a mudança política do País, ao lado do novo movimento sindical, na direção da democratização da sociedade. No entanto, nesse conflito, o movimento docente posicionou cada vez mais defensivamente, numa luta pela própria sobrevivência. Há, de certa forma, um paradoxo: à medida que o movimento sindical docente se fortalece, reagindo ao agravamento da situação salarial e à ameaça à universidade pública, também ele é dominado, bloqueado, assimilado à nova ordem econômico-política que fortalece o cooperativismo sindical. Nesse quadro, as limitações decorrentes da própria categoria dos docentes têm impedido o movimento docente de avançar politicamente na direção proposta pelas lideranças da ANDES-SN. O movimento é forte por causa do apoio que tem em sua base, mas esta base só se mobiliza à medida que a luta se trava no plano das reivindicações de salário, carreira, benefícios. 
O desafio com que se defronta o movimento docente é a superação dessas limitações. Se o movimento se orientar apenas para a defesa corporativa de privilégios, ele acabará sendo contido, aprisionado e anulado, não imediatamente, mas a médio e longo prazos. De certa forma, está acontecendo o que Fernandes previa há mais de 20 anos, quando estudou a questão da "Reforma Universitária". Então, afirmou: "Hoje contamos com uma 'universidade problema'. Amanhã contaremos com uma 'universidade corporativista', se não soubermos resguardar a reforma universitária e realizála como expressão da liberdade de pensamento crítico e da responsabilidade científica dos próprios universitários" (Fernandes, 1975, p. 19). Outro pensador brasileiro, Álvaro Vieira Pinto (1986), também tinha clareza ao defender a reforma universitária na perspectiva social, abrindo-se para o atendimento da maioria marginalizada pelo sistema. É notório que o movimento docente, nos seus primórdios, ainda na década de 70, enfatizava e praticava bem mais que hoje a integração com o "movimento estudantil". O sucesso das primeiras greves dos docentes deveu-se, em parte, ao apoio dos estudantes, tanto das IES públicas quanto das particulares. Hoje, porém, o movimento docente encontra-se cada vez mais afastado dos estudantes. Isso deveria preocupar as lideranças sindicais e acadêmicas.

Como sabemos, o corporativismo é um fenômeno altamente complexo. ANOEI reintroduziu essa forma de organização dos interesses que visa conciliar o conflito social (sob a denominação de "neocorporativismo"). Porém, nas nações desenvolvidas há sólidas instituições sociais democráticas (associações, sindicatos, partidos) que impõem limites à lógica própria do capitalismo oligopolista, de acumular o capital e de fragmentar e enfraquecer as organizações dos trabalhadores. No Brasil, devido à fragilidade de sua democracia, os efeitos das mudanças da conjuntura internacional acabam reforçando o caráter corporativista de seu modelo sindical oficial (atrelado ao Estado).

O discurso oficial, veiculado pela mídia, de combate ao corporativismo do movimento sindical, é altamente contraditório. $\mathrm{O}$ movimento sindical em geral é vítima de um modelo de organização econômico-política que neutraliza as lutas sociais em favor de mudanças estruturais. No caso do sindicalismo docente, por mais que se discuta a 
questão do corporativismo, ela não é a razão central do confronto entre o govemo e o movimento docente. Se o confronto permanecer somente no plano da reivindicação corporativa, mesmo que o movimento sindical se fortaleça e que o governo venha a fazer concessões, a Universidade permanecerá enquadrada na lógica do sistema econômico-político vigente.

Por isso, não é surpreendente que duras conquistas do movimento docente tenham sido anuladas, mesmo as conquistas salariais e de carreira. Pela estratégia da inflação, as classes dominantes anulam em pouco tempo as conquistas dos trabalhadores, obrigando-os a uma luta incessante. Da mesma forma, as contínuas ameaças aos direitos conquistados pelos docentes e servidores públicos (aposentadoria integral, estabilidade) reforçaram o corporativismo, acabando por enfraquecer a universidade pública e o próprio sindicato. Este, em conseqüência também das próprias contradições e ambigüidades, não está conseguindo sair do campo de defesa e travar a luta onde ela seria realmente decisiva.

O desafio que se coloca hoje para o movimento sindical docente é o de conciliar a luta defensiva, de caráter corporativo, com a contribuição que é específica da universidade enquanto instituição produtora de conhecimentos e formadora de dirigentes, de elites orgânicas. A universidade, em regra, sempre foi (e continua sendo) uma instituição "superior", comprometida com as classes dominantes, formando suas elites intelectuais e produzindo conhecimentos que beneficiam predominantemente essas mesmas classes e elites (Sobral, 1988). A crise atual da universidade decorre das transformações do capitalismo monopolista, que impôs o assalariamento e a degradação do trabalho intelectual, fazendo com que os docentes sejam, até certo ponto, igualados aos demais trabalhadores, assimilando inclusive a prática da luta sindical. A universidade passou, então, a viver no seu dia-a-dia o conflito social. Mas essa luta em defesa de melhores salários e condições de trabalho não implica necessariamente que a universidade deixe de cumprir sua função institucional. A questão de fundo está em compreender que a luta sindical não se contrapõe ao exercício da função de intelectual.

Gramsci propôs que se trabalhasse na "criação de elites intelectuais de um novo tipo", que fossem capazes de atuar em contato com o povonação, criando nova concepção de mundo e conduzindo, assim, a uma nova hegemonia. Nessa perspectiva, ele criticou a universidade de seu 
tempo: "A universidade, com exceção de alguns países, não exerce nenhuma função unificadora..."(Gramsci, 1986, p.29). Sua crítica se dirigia particularmente ao aspecto pedagógico, à relação professor-aluno: "nas universidades, o contato entre professores e estudantes não é organizado. O professor ensina à massa de ouvintes... e vai embora..." (Gramsci, 1988, p. 146). Como se sabe, Gramsci, a exemplo de Lenin, distinguiu e valorizou a função do intelectual como indispensável à transformação da sociedade.

Preservar a identidade do trabalho acadêmico não se contrapõe a lutar pela via sindical. À medida que os docentes entenderem isto e superarem preconceitos que impedem sua identificação enquanto trabalhadores, é possível que contribuam mais decisivamente para a transformação da sociedade. Essa contribuição integra a luta sindical dos docentes com a de outras categorias de trabalhadores; isso não exclui nem prescinde da atividade especificamente acadêmica.

A importância do trabalho acadêmico está relacionada ao que Bourdieu designou como poder simbólico, "cuja forma por excelência é o poder de fazer grupos". A atuação sindical em nada contraria o exercício desse poder; pelo contrário, o sindicalismo inscreve-se também no campo do poder simbólico.

Para mudar o mundo, é preciso mudar as maneiras de fazer o mundo, isto é, a visão do mundo e as operações práticas pelas quais os grupos são produzidos e reproduzidos. O poder simbólico, cuja forma por excelência é o poder de fazer grupos (...), está baseado em duas condições. Primeiramente, como toda forma de discurso performativo, o poder simbólico deve estar fundado na posse de um capital simbólico. O poder de impor às outras mentes uma visão, antiga ou nova, das divisões sociais depende da autoridade social adquirida nas lutas anteriores. O capital simbólico é um crédito, é o poder atribuído àqueles que obtiveram reconhecimento suficiente para ter condição de impor o da mobilização, ou de fazer existir por procuração, falando por ele enquanto porta-vOZ autorizado, só pode ser obtido ao término de um longo processo de institucionalização, ao término do qual é instituído um mandatário, que recebe do grupo o poder de fazer o grupo.

Em segundo lugar, a eficácia simbólica depende do grau em que a visão proposta está alicerçada na realidade. Evidentemente, a construção dos grupos não pode ser uma construção ex-nihilo. Ela terá tanto mais chances de sucesso quanto mais estiver alicerçada na realidade: isto é, como eu disse, nas afinidades objetivas entre as pessoas que se quer reunir. Quanto mais 
adequada for a teoria, mais poderoso será o efeito da teoria. O poder simbólico é um poder de fazer coisas com palavras (Bourdieu, 1990, p. 166-167).

O movimento sindical dos docentes universitários ganha importância para a universidade e para a sociedade à proporção que ele não perde sua especificidade (poder simbólico), isto é, que é capaz de explicitar para si próprio e para as demais categorias de trabalhadores o significado teórico de suas lutas. Isso implica também em esclarecer contradições implícitas na própria categoria docente. Diz Apple (1989, p.176): "Se eles (os professores) ocupam, de fato, uma localização de classe contraditória, então é possível iniciar uma importante caminhada em direção à educação política".

A luta corporativa foi e continua sendo importante para a defesa da universidade e dos salários e condições de trabalho dos docentes e servidores. Mas o alcance dessa luta depende do sentido que ultrapassa a dimensão corporativa. Será necessário ir além daquilo que o sistema econômico-político insiste em reservar aos movimentos e organizações sindicais, em geral. As palavras de Hobsbawm (1987, p.388-389) cabem também ao movimento sindical dos docentes universitários:

E apesar do fato de nossas gerações terem sofrido do capitalismo uma lavagem cerebral para acreditar que a vida é o que o dinheiro pode comprar, há mais nesse movimento do que pedidos de aumento de salário. Há mesmo mais que o desespero quanto a uma sociedade incapaz de dar a seus membros o que eles precisam, uma sociedade que força cada indivíduo ou cada grupo a cuidar de si próprio e não se importa com o resto. Já foi dito 'Dentro de cada trabalhador existe um ser humano tentando se libertar'. Na história da classe operária (...) já houve tentativas melhores e mais esperançosas de libertação dos seres humanos. Mas esta também é uma tentativa. Não adianta rejeitá-la, amaldiçoá-la e muito menos desejar que ela desapareça. Deve-se prestar atenção. Mas também de nada adiantará ignorar suas limitações.

\section{Referências bibliográficas}

ALMEIDA, Maria Herminia Tavares de. Dificil caminho: sindicatos e política na construção da democracia. In: REIS, Fábio Wanderley, 0'DONNELL, Guillermo (Orgs). A democracia no Brasil: dilemas e perspectivas. São Paulo: Vértice, Ed. Rev. dos Tribunais, 1988. 
ANDES-SINDICATO NACIONAL. Sindicato Nacional dos Docentes das Instituições de Ensino Superior. Proposta das Associações de Docentes e da ANDES )ara a Universidade Brasileira. Cadernos ANDES, n.2. Juiz de Fora, jul. 1986.

APPLE, Michael W. Educação e poder. Porto Alegre: Artes Médicas, 1989.

What reform talk does: creating new inequalities in education. Educational administration quarterly, 24, n.3, aug. 1988b, p.272-281. . Redefínición de là igualdad: populismo autoritario y restauración

----- conservadora. Revista de educación, n.28o, 1988a, p. 167-182.

ASSMANN, Hugo (Editor). A trilateral: nova fase do capitalismo mundial.4.ed. Petrópolis: vozes, 1990.

BERNARDO, João. Capital, sindicatos, gestores. São Paulo: Vértice, 1987.

BOITO JR, Armando. O sindicalismo de estado no Brasil. Tese de doutorado. São Paulo: USP, 1982.

BOURDIEU, Pierre. Coisas ditas. São Paulo: Brasiliense, 1990.

CADERNOS ANDES. Juiz de Fora, n.2, jul. 1986.

, LEVIN, Henry. Escola e trabalho no estado capitalista.

----- São Paulo: Cortez, 1987.

CHAUÍ, Marilena. Cultura e democracia: o discurso competente e outras falas. 3.ea. São Paulo: Moderna, 1982.

CMOPE(WCOTP). Principal ILO conventions and trade unions. Switzerland,

DREIFUSS, René. A internacional capitalista: estratégias e táticas do empresariado transnacional 1918-1986.2.ed. Rio de Janeiro: Espaço e Tempo, 1987.

FERNANDES, Florestan. Universidade brasileira: reforma ou revolução? São Paulo: Alfa-Omega, 1975.

FINKEL, Sara M. de. Crise de acumulação e resposta educacional da nova direita. In Teoria e educação, n.2, 1990, p.3-18.

GORZ, André. Crítica da divisão do trabalho.2.ed. São Paulo: Martins Fontes, 1989.

Adeus ao proletariado: para além do socialismo. Rio de Janeiro: Forense Universitária, 1987.

GRAMSCI, A. Os intelectuais e a organização da cultura.6.ed. Rio de Janeiro: Civilização Brasileira, 1988.

R. bras. Est. pedag., Brasília, v.74, n.178, p.555-580, set/dez. 1993 

Brasileira, 1986.

Concepção dialética da história.6.ed. Rio de Janeiro: Civilização

HOBSBAWM, Eric. 1989 - O que sobrou para os vitoriosos. Folha de São Paulo, $12 / 11 / 90$, p.A-3.

Mundos do trabalho: novos estudos sobre história operária. Rio de Janeiro: Paz e Terra, 1987. n.2, 1989.

. Trajetória do movimento operário. Trabalhadores, Campinas,

LAWN, Martin OZGA, Jenny. Trabajador de la ensenanza? Nueva valoración de los profesores. In Revista de Educación, n.285, p.191-215, 1988.

LOJKINE, Jean. A classe operária em mutações. Belo Horizonte: Oficina de Livros, 1990.

MARCUSE, H. A ideologia da sociedade industrial: o homem unidimensional .6.ed. Rio de Janeiro: Zahar, 1982.

MARINI, Ruy Mauro. A nova democracia latino-americana. Humanidades, v.4, n.13, maio/jul. 1987.

MILLS, C. Wright. A elite do poder .4.ed. Rio de Janeiro: Zahar, 1981.

OFFE, Claus. Capitalismo desorganizado: transformações contemporâneas do trabalho e da política. São Paulo: Brasiliense, 1989.

OHLWEILER, Otto Alcides. O capitalismo contemporâneo. Porto Alegre: Mercado Aberto, 1986.

PINTO, Álvaro Vieira. A questão da universidade. São Paulo: Cortez: Autores Associados, 1986.

POULANTZAS, Nicos. Poder político e classes sociais.2.ed. São Paulo: Martins Fontes, 1986.

RATTNER, Henrique. Impactos sociais da automação: o caso do Japão. São Paulo-Nobel, 1988.

REICH, Robert. The work of nations - preparing ourselves for the 2 Ist Century capitalism. New York: Alfred A. Knopf; 1991.

ROMANO, Roberto. Autoridade e poder na vida acadêmica. In: FÁVERO, Maria de Lourdes (Org.). A universidade em questão. São Paulo: Cortez: Autores Associados, 1989. 
SAES, Décio. Os intelectuais e suas associações. In: SOARES, Maria Susana Arrosa (Org.). Os intelectuais nos processos políticos da América Latina. Porto Alegre: Ed. da UFRGS, 1985.

SANTA ANA, Júlio de. A nova máscara do imperialismo. In: Encontros com a civilização brasileira, n.14, ago. 1979, p.35-49.

SOBRAL, Fernanda A. da Fonseca. Ciência, tecnologia e poder: os interesses sociais na pesquisa. Brasília: Departamento de Sociologia da Universidade de Brasília, 1988. Tese de doutorado.

VIEIRA, Sofia Lerche. Universidade federal nos anos 80: o jogo da política educacional. São Paulo, PUC-SP, 1990. Tese de doutorado.

Recebido em 22 de março de 1994

Pedro Rabelo Coelho, doutor em Educação pela Universidade Federal do Rio Grande do Sul (UFRGS), é professor titular do Departamento de Administração Escolar da Universidade Federal de Santa Maria (UFSM).

One of the objectives of this paper is to Understand the modifications of the capital ist modes of production at the end of the present Century, at the international as well as the national leveis. It attempts at the same time to explain the crisis of the Brazilian Public University, Identifying the challenges which are presented to those who Struggle for the integration of the academic work to the political process of bringing about a democratic Society. The paper is divided into two paris. The first part deals with a "new international economic order ", emphasizing mainly the appearance and the performance of the international organic elite as well as the scientific-technological revolution with its consequences for the labor division and the collective organization of Workers. The Second Hirt discusses the problem of the University teachers as Workers and their nvolvement in the political-syndicalist struggles. Finally this paper points out the challenges to befaced by the teachers movement in the construction of a truly public University. 
Cette étude a pour but, dabord, comprendre les transformations du moyen de production capitaliste à là fin de cette siècle, qu 'il soit dans là conjoncture internationale ou alors dans là nationale, en essayant d'expliquer là crise de l'Université publique brésilienne ensuite reconnaitre les défis de ceux qui luttent dans là perspective d'intégrer le travail académique au processus politique de là construction d 'une société démocratique. Elle est organisée en deuxparties: là première traité de le "nouveau ordre économique international" (NOEI) en relevant surtout Vapparition de l 'elite organique internationale et là révolution scientifique-technologique avec ses consequences dans lepartage du travail et dans l 'organization collective ouvrière. La deuxième discute là problématique des enseignants Universitaires dans là condition d 'ouvrier et leurparticipation dans les luttespolitique-syndicales, en arrivant à là fin vers les défis que le mouvement des enseignants trouve lors de là construction d'une véritable Université publique.

Compreender Ias transformaciones del modo de producción capitalista en este final de siglo, tanto en el plano de là conjuntura internacional como de Ia nacional, buscando explicar Ia crisis de là Universidad pública brasilera, y reconocer los desafios que se présentant a los que luchan en là perspectiva de integrar el trabajo acadêmico en el proceso político de construcción de una sociedad democrática: ésos son los objetivos de este estúdio. El está organizado en dos partes. La primera aborda là "nueva orden econômica internacional"(NOEI), destacando principalmente el aparecimiento y Ia actuación de là elite orgânica internacionaly là revolución científico-tecnológica con sus consecuencias para Ia división del trabajo y là organización colectiva de los trabajadores. La segunda parte discute là problemática de los docentes universitários en su calidad de trabajadores y su comprometimiento en Ias luchas político-sindicales, haciendo mención, al final, al desafio que el movimiento docente enfrenta para là construcción de una verdadera Universidad pública. 